\title{
Which trees should be removed in thinning treatments?
}

\author{
Timo Pukkala ${ }^{1 *}$, Erkki Lähde ${ }^{2}$ and Olavi Laiho ${ }^{2}$
}

\begin{abstract}
Background: In economically optimal management, trees that are removed in a thinning treatment should be selected on the basis of their value, relative value increment and the effect of removal on the growth of remaining trees. Large valuable trees with decreased value increment should be removed, especially when they overtop smaller trees.

Methods: This study optimized the tree selection rule in the thinning treatments of continuous cover management when the aim is to maximize the profitability of forest management. The weights of three criteria (stem value, relative value increment and effect of removal on the competition of remaining trees) were optimized together with thinning intervals.

Results and conclusions: The results confirmed the hypothesis that optimal thinning involves removing predominantly large trees. Increasing stumpage value, decreasing relative value increment, and increasing competitive influence increased the likelihood that removal is optimal decision. However, if the spatial distribution of trees is irregular, it is optimal to leave large trees in sparse places and remove somewhat smaller trees from dense places. However, the benefit of optimal thinning, as compared to diameter limit cutting is not usually large in pure one-species stands. On the contrary, removing the smallest trees from the stand may lead to significant (30-40 \%) reductions in the net present value of harvest incomes.
\end{abstract}

Keywords: Continuous cover forestry, Tree selection, High thinning, Optimal management, Spatial distribution, Spatial growth model

\section{Background}

A tree is financially mature for cutting when its relative value increment falls below the guiding rate of interest (Davis and Johnson 1987; Knoke 2012). However, the value increment may improve in the future, due to e.g. changes in the proportions of timber assortments that can be obtained from the tree. Therefore, Duerr et al. (1956) advice to calculate the relative value increment for several coming time periods and classify the tree as financially mature if the highest projected rate of value increase is smaller than the guiding rate of interest.

In Finland and many other countries the main timber assortments are pulpwood and saw log, of which saw $\log$ is more valuable. Figure 1 (bottom) shows that, in Finnish conditions, the consequence of unequal prices of different timber assortments is the existence of peaks in

\footnotetext{
* Correspondence: timo.pukkala@uef.fi

'University of Eastern Finland, PO Box 111, 80101 Joensuu, Finland Full list of author information is available at the end of the article
}

relative value increment when the stem attains sufficient dimensions for pulpwood log, first saw log, second saw log etc. At later ages, when most of the volume is already saw $\log$, the peaks gradually disappear and the relative value increment decreases monotonously with increasing tree age and size. If the tree has passed all the value jumps, it is enough to analyze the current value increment to judge whether the tree is financially mature for cutting. It is noteworthy, however, that different trees of the stand do not reach financial maturity at the same age or diameter (Fig. 1 bottom; Knoke 2012). This is because of genetic variation, spatial variation in site productivity, and differences in the competitive positions of the trees. The last factor can be taken into account in financial analysis if distance-dependent growth models are used to predict increment.

Figure 1 (top) shows that a regular spatial distribution of trees makes it possible to maintain sufficient value increments with larger average tree diameter as compared

\section{Springer}



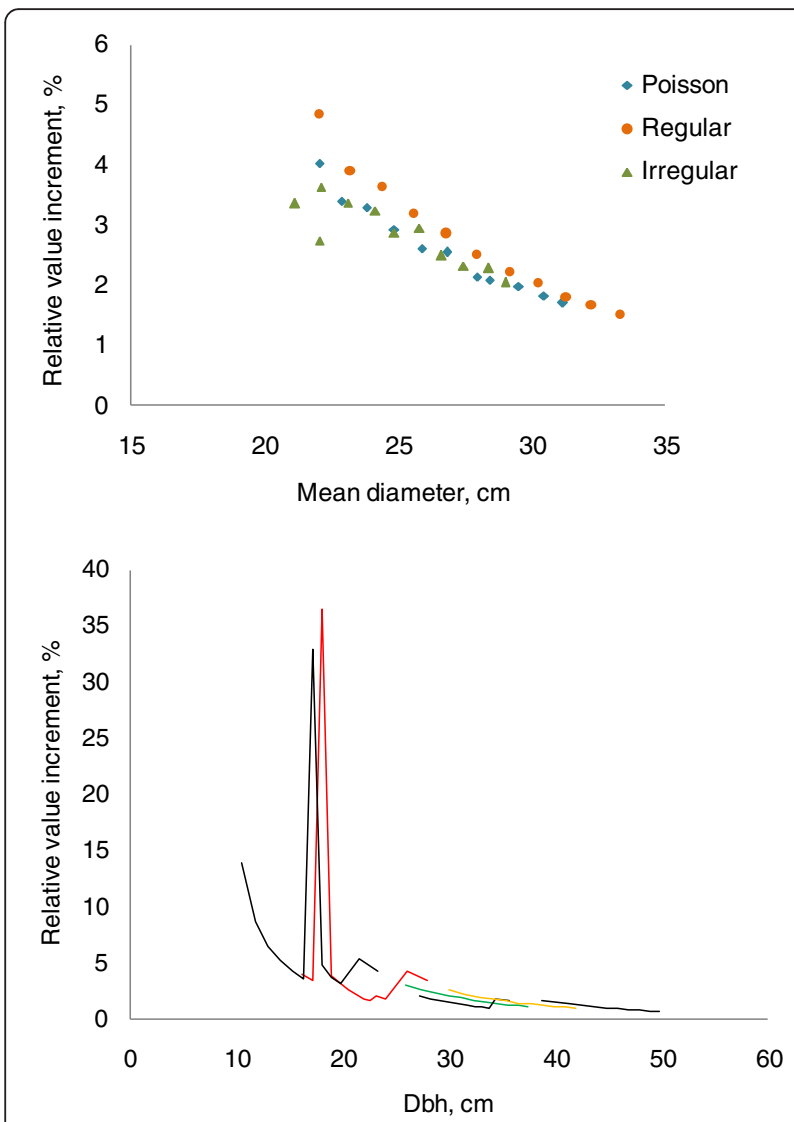

Fig. 1 Top: Relative value increment of uneven-sized spruce stands in 50-year simulations when there are no cuttings and the spatial distribution of trees is Poisson, regular (systematic) or irregular (aggregated). Bottom: development of relative value increments of six trees in the Poisson distributed stand in 50-year simulation

to more aggregated spatial arrangements. This means that, on the average, a tree reaches financial maturity at smaller diameter in irregular spatial distribution. However, some of the trees in an aggregated spatial tree distribution, growing in sparsely populated places or being surrounded by small trees, may grow better than a similar tree would grow in a regular stand, which postpones the financial maturity of these trees.

As Davis and Johnson (1987) pointed out, the effect of tree removal on the growth of remaining trees should also be taken into account when deciding when a tree should be harvested and which trees should be removed. Removing a large tree leads to improved value increment in smaller trees. This calls for cutting large trees earlier than their relative value increment suggests. The removal of a large tree may improve the productivity of several remaining trees and increase the relative value increment of the whole residual stand.

The capital invested in wood production consists of the value of the trees plus the value of bare land. If bare land has a positive value this means that a tree is financially mature at higher relative value increment than indicated by the guiding rate of return. This is because the value increment must be compared to the opportunity cost of the tree and the piece of land occupied by the tree. Bare land value and the effect of tree removal on the growth of remaining trees both increase the rate of value increment at which cutting is optimal decision.

The above analysis suggests that it is optimal to remove the largest trees in a thinning treatment. However, unequal competitive status of trees, as well as unequal effect of tree removal on the growth of surrounding trees, makes the decision more complicated than for instance applying diameter limit cutting. A detailed analysis of optimal tree selection needs a distance dependent growth model, or at least the calculation of value increments and the effects of tree removal at individual tree level.

Although the overall principles that should determine tree selection in thinning have been understood and described already several decades ago (Duerr et al. 1956; Davis and Johnson 1987) few studies have actually optimized the selection of removed trees. An exception is the study of Pukkala and Miina (1998) who optimized a tree selection rule which was based on the effect of tree removal on the competitive positions of remaining trees. It was found that it was optimal to thin from above, i.e. remove large trees.

This study proposed a more straightforward approach to optimizing tree selection: the criteria of the cutting rule were the tree's stumpage value, its value increment, and the effect of removal on the growth of surrounding trees. It was assumed that increasing stumpage value, decreasing relative value increment and increasing competitive effect increase the likelihood of removal. Another hypothesis was that the optimal order of tree removal is less strongly correlated with tree diameter in irregular spatial distributions, as compared to regular tree arrangements. A third hypothesis was that, when net present value is maximized, it is optimal to remove trees at higher relative value increment than the discount rate that is used to calculate net present value.

\section{Methods}

Three different sample plots of Norway spruce $(50 \mathrm{~m}$ by $50 \mathrm{~m}$ ) with the same diameter distribution but different spatial distribution of trees were generated for the analyses. The first plot had a Poisson distribution of trees (henceforth referred to as Poisson stand). The $x$ and $y$ coordinates of trees were drawn from uniform distribution. The second stand was regular, and the third stand was very irregular (aggregated). Regular spatial distributions can be easily achieved by silvicultural treatments and the irregular distribution might be a result of removing all birches from a naturally emerged mixture of 
birch and spruce. Spruces may be very irregularly distributed in such stands. The mean diameter of each initial stand was about $22 \mathrm{~cm}$, stand basal area was $17 \mathrm{~m}^{2} \cdot \mathrm{ha}^{-1}$ and the number of trees per hectare was 1200 . The stands were assumed to grow on mesic site in Central Finland.

The models of Pukkala et al. (2013) for diameter increment, tree survival and ingrowth were used in simulation. The models are based on about 60,000 diameter increment and survival observations in different stand types. The models can be used in both even-sized and uneven-sized stands. However, the models are not spatial. When the models were used in this study, the predictors which describe competition (stand basal area, $G$, and basal area in larger trees, $B A L$ ) were calculated from trees that were within 10 meters from the tree for which predictions were calculated. This is justified because most of the modelling data of Pukkala et al. (2013) were measured on plots with approximately $10-\mathrm{m}$ radius. However, to make the growth simulator distance dependent, both $G$ and $B A L$ were calculated as the average $G$ $\left(\mathrm{m}^{2} \cdot \mathrm{ha}^{-1}\right)$ or $B A L\left(\mathrm{~m}^{2} \cdot \mathrm{ha}^{-1}\right)$ within $10 \mathrm{~m}$, within $10 / 2 \mathrm{~m}$ (5 $\mathrm{m})$, and within $10 / 3 \mathrm{~m}(3.33 \mathrm{~m})$. As a result, the closest trees had a larger influence on $G$ and $B A L$. This is in accordance with several studies, which show that the effect of neighbor trees on the growth of a subject tree decreases with increasing distance (see e.g. Miina and Pukkala 2000).

Mortality was simulated by comparing the tree's survival probability to random number distributed uniformly between 0 and 1 . If the random number was larger than the survival probability, the tree was assigned as dead. Ingrowth (number of ingrowth trees) was predicted with the unmodified model of Pukkala et al. (2013) but spatial criterion was used to choose the places for ingrowth trees. Fifty candidate positions were generated for each ingrowth tree and the competition index proposed by Miina and Pukkala (2000; their Equation 6b)was calculated for each location. The tree was placed to that location which had the lowest completion index. The procedure mimics the observed dynamics of spruce stands (e.g. Eerikäinen et al. 2007) in which ingrowth trees appear in openings and places with little competition by larger trees.

The optimization problem consisted of selecting the thinning intervals and the weights of the three criteria of the following tree selection rule:

$$
\begin{aligned}
\text { RemovalScore }= & w_{1} \text { Value }+w_{2} \text { RelativeValueIncrement } \\
& +w_{3} \text { BALeffect }
\end{aligned}
$$

where Value is the stumpage value of the stem, RelativeValueIncrement is the predicted 5-year value increment divided by the stumpage value of the stem, BALeffect is the total reduction in the BALs of neighbor trees in case the tree is removed, and $w_{1}, w_{2}$ and $w_{3}$ are optimized parameters which determine the effect of the three criteria on the order of tree removal. The BAL effect was calculated in the same way as BALs were calculated in growth prediction, i.e. by giving more weight to close neighborhood. A removed tree affected most within $3.33 \mathrm{~m}$, somewhat less within $3.33-5 \mathrm{~m}$, still less within $5-10 \mathrm{~m}$ and not at all beyond 10 meters.

The optimized parameters were thinning intervals and parameters $w_{1}, w_{2}$ and $w_{3}$ of the tree selection rule. The problem formulations correspond to continuous cover management since planting was not an option when stand development was simulated. The remaining basal area was calculated with the following model, which is based on 20,583 optimized cuttings of 6,861 stands located in different parts of Finland. All optimizations meet the constraints of Finnish forestry legislation:

$$
\begin{aligned}
G_{\text {remain }}= & \exp \left(8.149-4.656 D^{0.1}+0.0221 G_{\text {total }}\right. \\
& +0.211 G_{\text {pine }} / G_{\text {total }}+0.254 G_{\text {spruce }} / G_{\text {total }} \\
& -0.0327 \sqrt{ } r-0.0333 M T-0.0992 V T \\
& -0.164 C T)
\end{aligned}
$$

where $G_{\text {remain }}$ is remaining basal area $\left(\mathrm{m}^{2} \cdot \mathrm{ha}^{-1}\right), D$ is basal-area-weighted mean diameter of trees $(\mathrm{cm}), G_{\text {total }}$ is stand basal area before thinning $\left(\mathrm{m}^{2} \cdot \mathrm{ha}^{-1}\right), G_{\text {pine }}$ is basal area of pine $\left(\mathrm{m}^{2} \cdot \mathrm{ha}^{-1}\right), G_{\text {spruce }}$ is basal area of spruce $\left(\mathrm{m}^{2} \cdot \mathrm{ha}^{-1}\right), r$ is discount rate (\%), and $M T, V T$ and $C T$ are indicator variables for mesic, sub-xeric and xeric site, respectively.

When a thinning was simulated, trees were removed according to their removal score (Eq. 1) until the remaining basal area was equal to the value calculated with Eq. 2. In another set of optimizations, also the remaining basal was optimized. These optimizations may not always meet the current legal limits of Finland.

A $10-\mathrm{m}$ wide buffer zone was generated around the plot when stand development was simulated (when computing the predictors of the models), and the buffer was removed after completing a simulation time step. The buffer was generated by assuming that the plot was surrounded by similar plots on all sides. Since the models that were used in growth simulation have five-year time step, stand development was simulated in 5-year steps.

Computation of the removal scores of trees involved the calculation of the stumpage value, 5-year value increment and BAL effect for every tree. To obtain the stumpage value, taper models (Laasasenaho 1982) were used to calculate assortment volumes, which were multiplied by their unit prices. The assortments were saw $\log \left(50 € \cdot \mathrm{m}^{-3}\right.$, minimum top diameter $16 \mathrm{~cm}$, minimum length $4 \mathrm{~m}$ ), and pulpwood $\left(15 € \cdot \mathrm{m}^{-3}\right.$, minimum top diameter $9 \mathrm{~cm}$, 
minimum length $2 \mathrm{~m}$ ). To calculate value increment, the diameter (dbh) and height of the tree were incremented by five-year growth, and assortment volumes corresponding to the incremented dimensions were calculated with the taper model.

The obtained stumpage values, value increments and BAL effects were used to calculate the removal scores for all trees, and the tree with the highest score was removed. Since a tree removal may affect the competitive influences, value increments and removal scores of remaining trees, the BAL effects and value increment predictions of all remaining trees were updated after every tree removal. This involved removing the buffer, generating the buffer again, and calculating the BAL effects and value increments again. Removing and adding the buffer after every tree removal was based on the assumption that the forest that surrounds the plot is thinned simultaneously with the plot.

Three next thinnings were optimized in the analyses of this study. The NPV of the ending growing stock (residual stand after the third thinning) was predicted with the model (see Pukkala 2015b). The model prediction, once discounted to the starting year of simulation, gives the $N P V$ of all incomes and costs that are later than the last optimized cutting. It has been shown (Pukkala 2015a, 2015b) that using the model for estimate the NPV of distant cuttings has no major effect on the optimization results for the next cuttings, as compared to a higher number of optimized cuttings.
Since the simulation involves stochasticity in mortality and ingrowth, every simulation that was conducted during the optimization run was repeated 10 times and the mean $N P V$ of the repeated simulations was used as the objective function (returned to the optimization algorithm). The direct search method of Hooke and Jeeves (1961) was used in optimization. Every optimization was repeated 5 times, each direct search starting from the best of 100 random combinations of optimized variables. The best solution (highest $N P V$ ) was taken as the optimal solution. $N P V$ was calculated with $3 \%$ discount rate.

\section{Results and discussion}

\section{Remaining basal area not optimized}

Optimizations in which the remaining basal area was not optimized suggested immediate thinning in all three stands, another thinning after 10 years, and a third thinning 10 years later (Table 1, boldface). However, there was some variation between repeated optimizations in the cutting intervals, especially in the irregular stand. Looking at the NPVs of the solutions suggests that those solutions that propose intervals other than 10 years may be sub-optimal, i.e., the algorithm has converged to local optimum.

The ranking of the three stands in terms of $N P V$ was logical. The regular stand produced the highest $N P V$ whereas the highly irregular stand produced clearly smaller economic benefit than the other stands (Table 1).

Table 1 Net present values and optimal values of decision variables for Poisson, regular and irregular stand in 5 repeated optimizations when the remaining basal area of thinning was calculated with a model (Eq. 2)

\begin{tabular}{|c|c|c|c|c|c|c|}
\hline NPV $\left(€ \cdot h a^{-1}\right)$ & Years to 1st thinning & Years to 2nd thinning & Years to 3rd thinning & $w_{1}$ (stem value) & $w_{2}$ (value increment) & $w_{3}$ (BAL effect) \\
\hline & Poisson stand & & & & & \\
\hline 9133 & 0 & 10 & 10 & 0.37 & -0.25 & 0.38 \\
\hline 9121 & 0 & 10 & 15 & 0.24 & -0.47 & 0.29 \\
\hline 9127 & 0 & 10 & 10 & 0.48 & -0.50 & 0.02 \\
\hline 9032 & 0 & 15 & 15 & 0.43 & -0.27 & 0.29 \\
\hline \multirow[t]{2}{*}{9105} & 0 & 10 & 10 & 0.29 & -0.05 & 0.66 \\
\hline & Regular stand & & & & & \\
\hline 9319 & 0 & 10 & 10 & 0.35 & -0.31 & 0.34 \\
\hline 9237 & 0 & 10 & 20 & 0.49 & -0.27 & 0.24 \\
\hline 9304 & 0 & 15 & 10 & 0.78 & -0.04 & 0.18 \\
\hline 9289 & 0 & 15 & 15 & 0.46 & -0.29 & 0.26 \\
\hline \multirow[t]{2}{*}{9313} & 0 & 10 & 15 & 0.30 & -0.13 & 0.57 \\
\hline & Irregular stand & & & & & \\
\hline 8247 & 0 & 10 & 10 & 0.42 & -0.13 & 0.45 \\
\hline 6852 & 0 & 25 & 45 & 0.46 & -0.27 & 0.26 \\
\hline 8266 & 0 & 10 & 10 & 0.32 & -0.43 & 0.25 \\
\hline 7511 & 0 & 30 & 10 & 0.38 & -0.30 & 0.32 \\
\hline 8238 & 0 & 10 & 35 & 0.50 & 0.01 & 0.52 \\
\hline
\end{tabular}

Optimization result with the highest NPV is indicated with boldface 
The signs of the parameters of the removal score function were logical: high stem value and high BAL effect (high reduction in the competition of remaining trees) increased the score, and high relative value increment decreased it. Valuable trees with low value increment and strong competitive effect on other trees were the first ones to leave. As a result, thinnings from above were conducted, as can be seen from the maps of Fig. 2.

A closer inspection of the diameters of the removed and remaining trees (Fig. 3) revealed that the thinnings of the regular stand resembled diameter limit cutting. There were only one or two diameter classes which included both remaining and removed trees. In the first thinning of the Poisson forest, there were 4 diameter classes $(8 \mathrm{~cm}$ diameter range) having both remaining and removed trees. This range was $12 \mathrm{~cm}$ in the irregular stand. Large trees were left in sparse places and rather small trees were removed from dense places.

The diagrams of Fig. 4 (bottom right) show that, in the regular stand, the order of removal followed decreasing breast height diameter fairly closely. The selection score correlated closely with both dbh and relative value increment, suggesting that either of these variables alone could be used as the harvesting criterion in a regular stand. In the other stands, the order of removal did not follow decreasing dbh equally closely. In both Poisson and regular stands, most trees removed in the first thinning were larger than $25 \mathrm{~cm}$.

The situation was different on the irregular stand, in which several removed trees were smaller than $25 \mathrm{~cm}$. To have a sufficient remaining basal area, some large trees were left to continue growing (Figs. 2 and 3). In the irregular stand, the removal score did not correlate strongly with $\mathrm{dbh}$ or relative value increment. In this stand, the BAL effect of tree removal varied much more than in the other stands (Fig. 4 bottom left) and had a stronger influence on the removal score than in the other stands. This cannot be concluded from the weights of BAL effect in Table 1 since the effect of the criterion depends on both the weight and the range of variation in the criterion variable in a particular stand and thinning. As a conclusion, when thinning an irregular stand, more importance should be given to the reduction of competition due to tree removal.

Table 1 shows that repeated optimizations result in different weights of the criteria of the removal score,

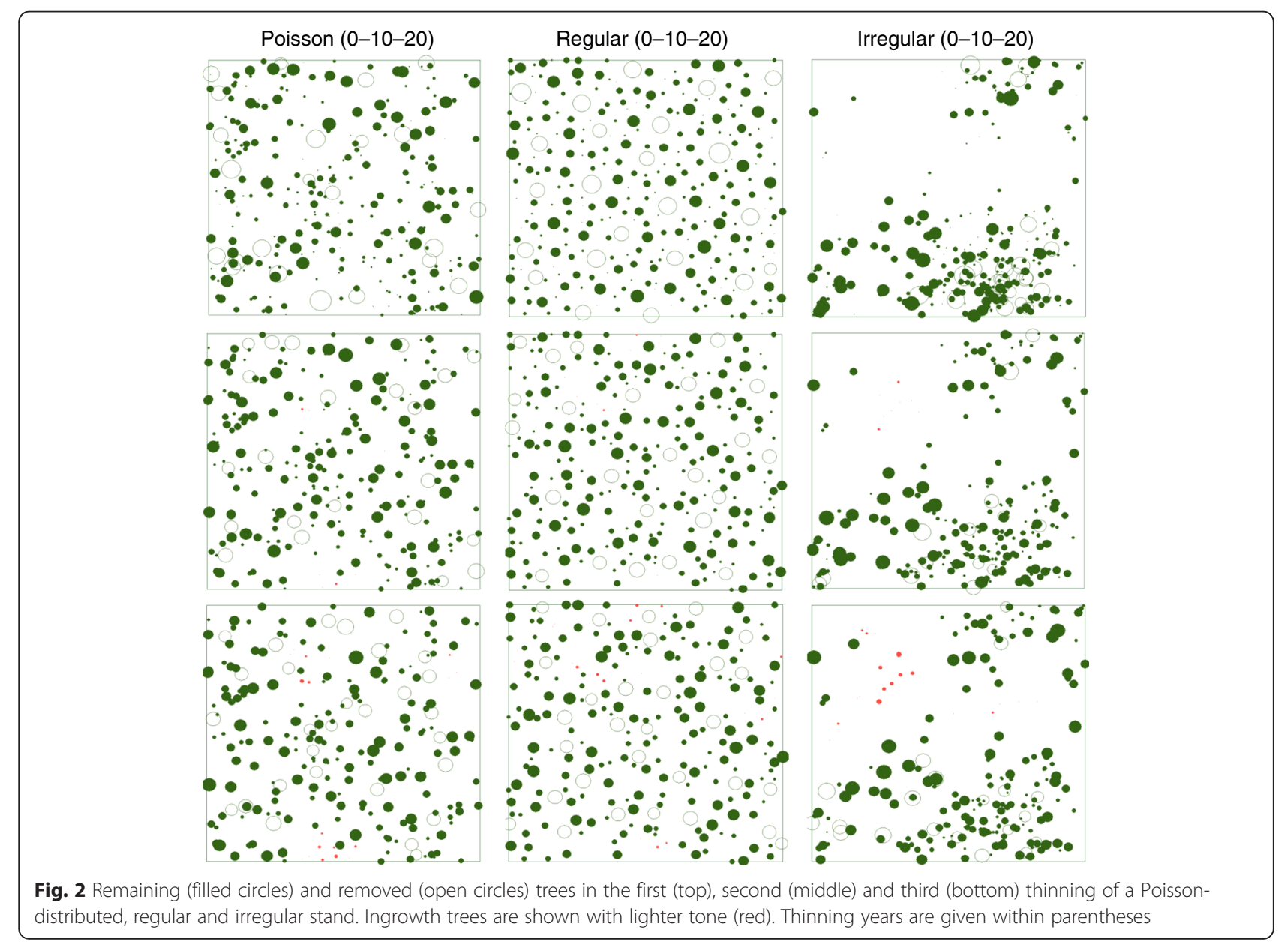




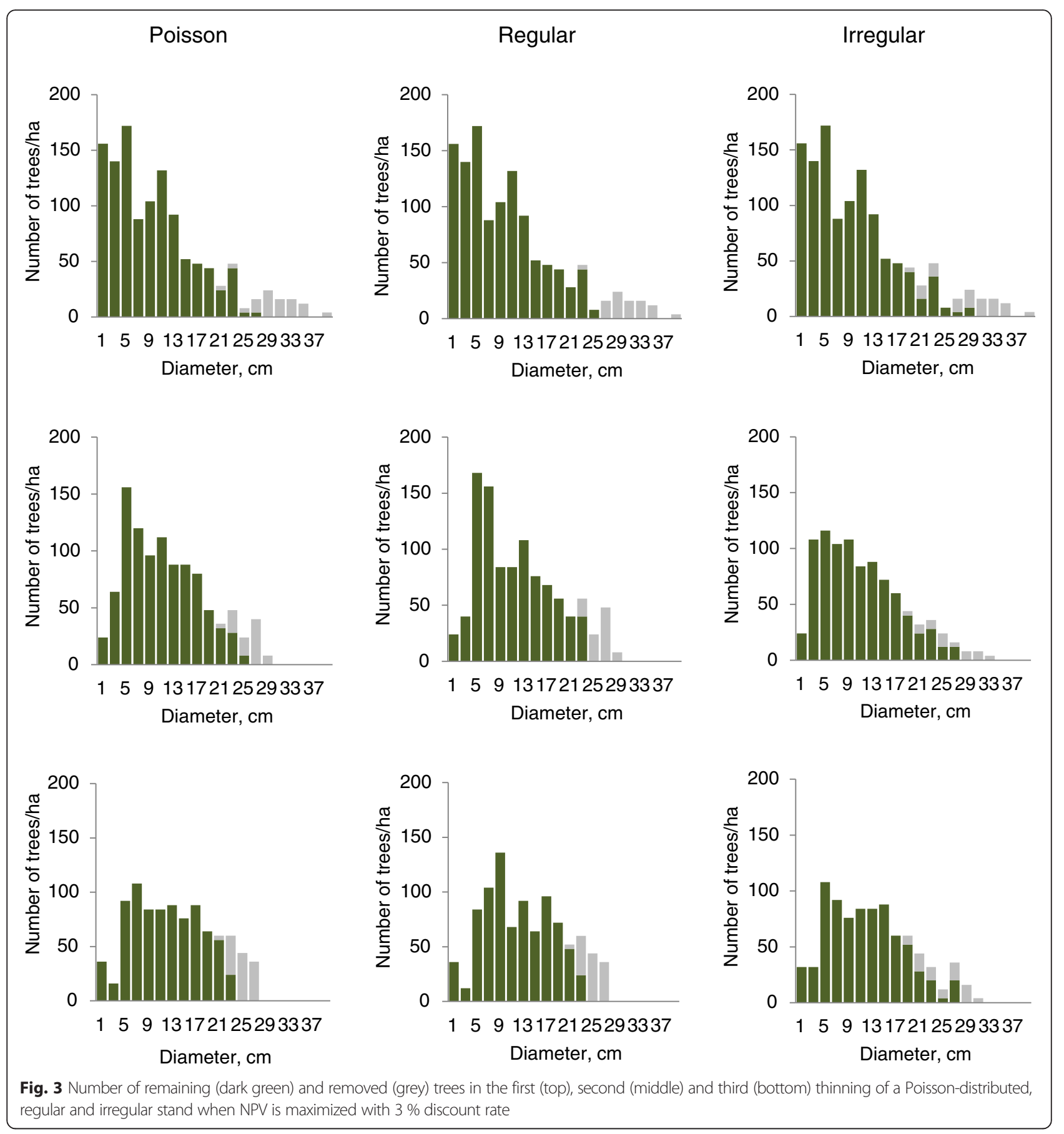

suggesting that there is much uncertainty in this respect. However, since the three criteria correlate with each other, the removal score may be fairly similar with different weights. This means that, although there is uncertainty about the exact weights of the removal criteria, there is less uncertainty about the removal order of trees. This can be seen from Fig. 5, which shows the locations of trees removed in the first thinning of the Poisson forest when the five different solutions of Table 1 were used to select the trees. Almost the same trees were removed when using different values for weights $w_{1}, w_{2}$ and $w_{3}$. Three trees were removed in only 1 solution and another three trees were removed in less than five solutions. All the other trees were removed in all solutions. Therefore, high variation in the obtained weights of the removal criteria bring only little uncertainty in tree selection. 

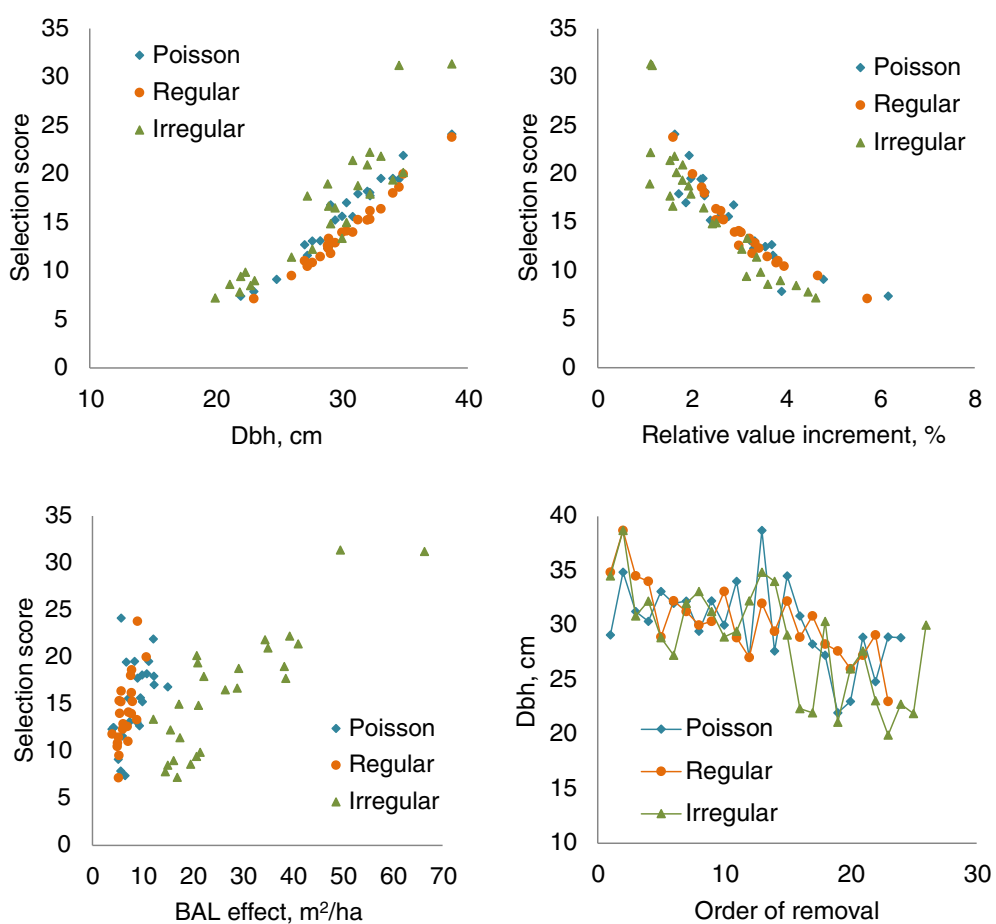

Fig. 4 Correlation of the tree selection score of the first thinning with dbh, relative value increment and BAL effect (reduced competition of other trees if the tree is removed). The bottom-right diagram shows the dbh of the removed trees as a function of the order of removal (trees on the left are removed first and trees on the right are the last trees removed)

Another simulation was done by applying the optimal weights of the thinning rules (boldface rows in Table 1) of the three different stands to the first thinning of the Poisson stand (Fig. 6). The results show again that nearly the same trees were removed from the Poisson forest

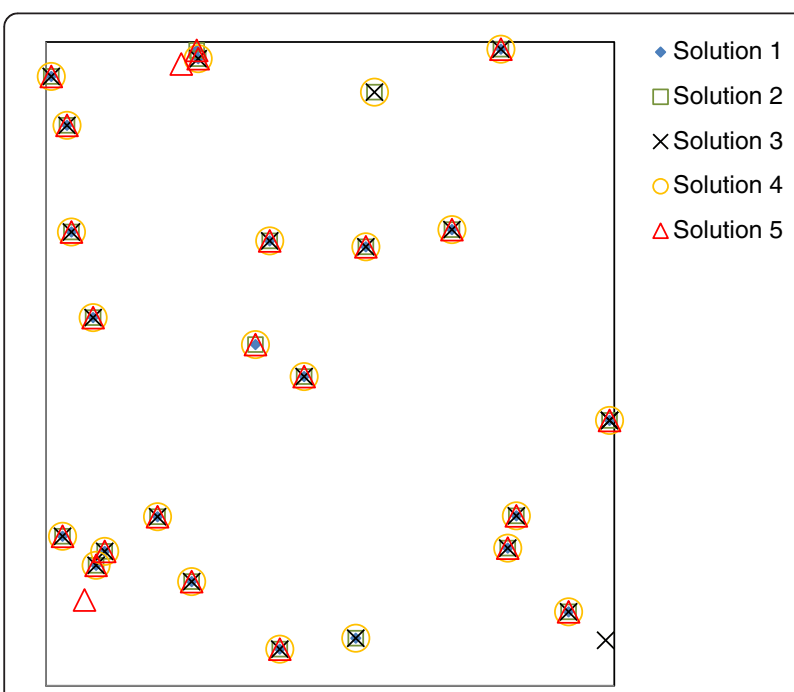

Fig. 5 Location of trees removed in the first thinning of the Poisson stand when tree selection is based on five different solutions of the optimization problem. When the symbols of different solutions coincide, the same tree is removed in all solutions when applying the optimal tree selection rule of regular, irregular or Poisson stand. This result implies that the same tree selection rule could be used in all spatial distributions, which may sound counterintuitive in the light of the diagrams of Fig. 4. However, even though the

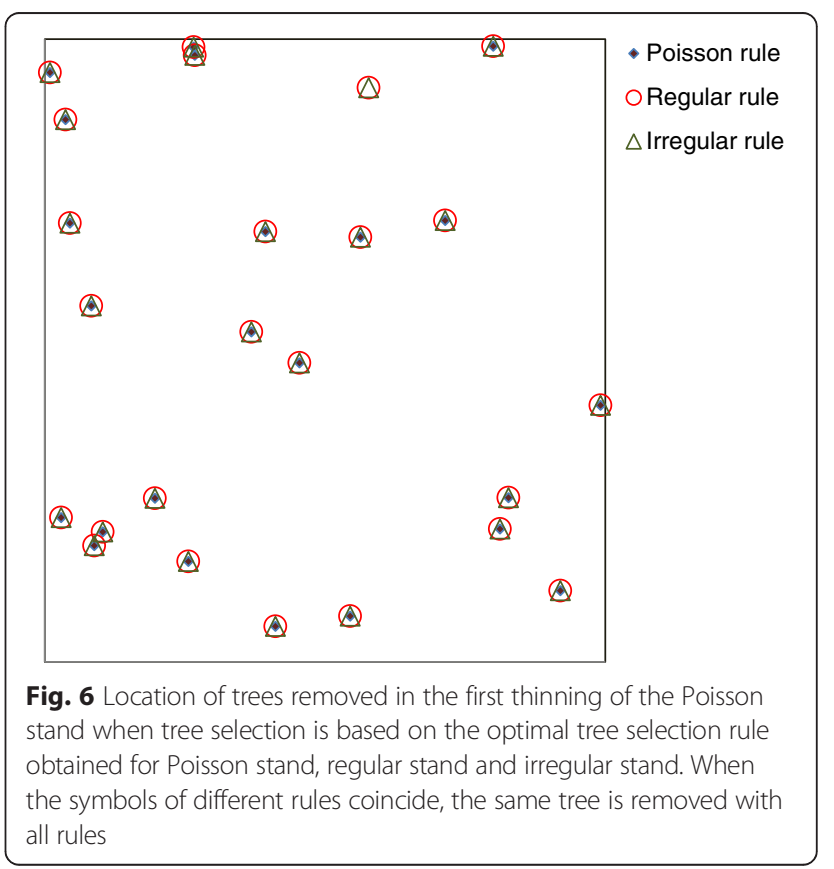


weight of e.g. BAL effect would be the same in all stands, the influence of BAL effect on tree removal would be stronger in the irregular stand, due to greater variation of BAL effect in this stand.

\section{Remaining basal area optimized}

When the remaining basal area was optimized together with the thinning intervals and tree selection rule, the $N P V$ of the optimal schedule increased by $4-5 \%$ as compared to optimizations in which remaining basal area was calculated with Eq. 2 (Tables 1 and 2). The remaining basal areas were now $6.5-8.9 \mathrm{~m}^{2} \cdot \mathrm{ha}^{-1}$ whereas they were $10-11 \mathrm{~m}^{2} \cdot \mathrm{ha}^{-1}$ when calculated with the model. The thinning intervals became longer in the Poisson and regular stands. It can be concluded that the requirement for a certain minimum residual basal area decreased the profitability of forest management in the three analyzed stands.

As a consequence of stronger thinnings, more ingrowth appeared in the stands, especially in the Poisson and regular stands, as compared to previous optimizations (Fig. 7). The thinning was extended to smaller diameters (Fig. 8), and the diameter range that had both remaining and removed trees, became narrower. This means that when remaining basal area was not restricted, optimal thinning resembled more diameter limit cutting, also in the aggregated spatial distribution.

The optimality of diameter limit cutting was further inspected by removing the trees according to dbh, starting from the largest tree ('High thinning' in Fig. 9). For comparison, simulations were also conducted so that the smallest trees were removed in the thinning treatments ('Low thinning' in Fig. 9). The results show that systematic diameter limit cutting was not much worse than optimal tree selection. Thinning from below would be a clearly inferior management approach.

\section{Effect of discount rate}

The previous optimizations used $3 \%$ discount rate. When remaining basal area was optimized in the Poisson stand (together with thinning intervals and tree selection rule), lower discount rate $(1 \%)$ led to clearly longer thinning intervals, higher pre-thinning basal areas, larger mean tree diameters, and slightly higher post-thinning basal areas and mean diameters, compared to $3 \%$ discount rate
(Fig. 10). Increased discount rate (5\%) resulted in 10-year thinning interval, lower remaining basal area and smaller mean tree size of the residual stand. When the discount rate was $1 \%$, the largest trees of the stand were $35 \mathrm{~cm}$ in $\mathrm{dbh}$ when the thinning was conducted. With $5 \%$ discount rate the thinning was conducted when the largest trees reached $25 \mathrm{~cm}$ breast height diameter.

The effect of discount rate was the most clear in growing stock value (Fig. 10, bottom left). When the discount rate was $1 \%$, the stumpage value of the growing stock was $8000 € \cdot \mathrm{ha}^{-1}$ at the second thinning and $13000 € \cdot \mathrm{ha}^{-1}$ at the third thinning. With $5 \%$ discount rate the prethinning growing stock value was only about $2200 € \cdot \mathrm{ha}^{-1}$.

When $N P V$ was maximized with $1 \%$ discount rate, it was optimal to thin the stand when its relative value increment was $2-3 \%$. With $3 \%$ discount rate the stand was thinned at 4.5-6\% value increment, and at with $5 \%$ discount rate at $8 \%$ value increment. When the discount rate was $3 \%$, in the first thinning of the Poisson stand about half if the removed trees had a relative value increment of about $2 \%$ and the rest had 3-6\% rate of value increment (Fig. 11, top). However, the first thinning, which was immediately, was most probably later than its optimal timing would have been. In later thinnings, $50 \%$ of removed trees were removed at about $4 \%$ rate of value increment and the rest were removed at higher, up to $7 \%$ value increment.

In the second thinning of the Poisson stand, trees were removed at $2-7 \%$ value increments when discount rate was $1 \%$, at $3-7 \%$ increments when discount rate was $3 \%$ and at $5-14 \%$ value increments when discount rate was $5 \%$ (Fig. 11, bottom). This is in line with the hypothesis of the study, according to which it is optimal to remove a tree at higher relative value increment than the guiding rate of interest. This is because of the opportunity cost of bare land and the fact that tree removal improves the relative value increment of remaining trees.

\section{Conclusions}

The results suggest that it is nearly optimal to select the trees that are removed in a thinning treatment on the basis of breast height diameter, starting from the largest tree. However, in irregular spatial distributions, the competition faced by the tree and the effect of removal on

Table 2 Net present values and optimal values of decision variables for Poisson, regular and irregular stand when the remaining basal area $(G)$ was optimized together with thinning intervals and tree selection rule

\begin{tabular}{|c|c|c|c|c|c|c|c|c|c|c|}
\hline \multirow[t]{2}{*}{ Stand } & \multirow[t]{2}{*}{$\operatorname{NPV}\left(€ \cdot \mathrm{ha}^{-1}\right)$} & \multicolumn{2}{|c|}{ 1st thinning } & \multicolumn{2}{|c|}{ 2nd thinning } & \multicolumn{2}{|c|}{ 3rd thinning } & \multirow[t]{2}{*}{$w_{1}$ (stem value) } & \multirow[t]{2}{*}{$w_{2}$ (value increment) } & \multirow[t]{2}{*}{$w_{3}$ (BAL effect) } \\
\hline & & Years & $G$ & Years & $G$ & Years & $G$ & & & \\
\hline Poisson & 9477 & 0 & 6.9 & 15 & 8.9 & 20 & 7.4 & 0.33 & -0.45 & 0.22 \\
\hline Regular & 9680 & 0 & 6.5 & 15 & 7.7 & 20 & 7.6 & 0.68 & -0.25 & 0.07 \\
\hline Irregular & 8671 & 0 & 6.9 & 10 & 8.6 & 10 & 6.8 & 0.83 & -0.09 & 0.08 \\
\hline
\end{tabular}




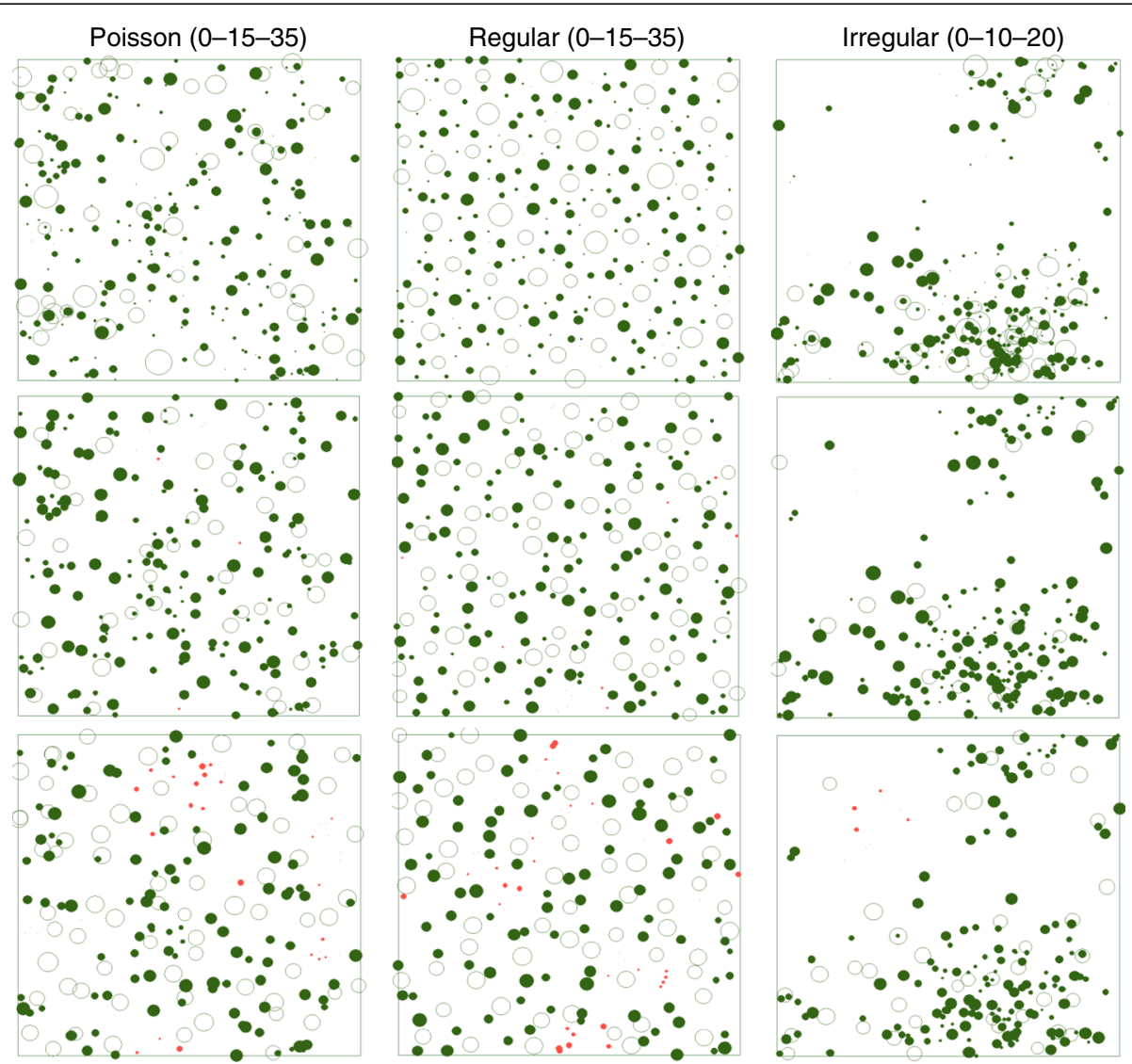

Fig. 7 Remaining (filled circles) and removed (open circles) trees in the first (top), second (middle) and third (bottom) thinning of a Poissondistributed, regular and irregular stand when the remaining basal area is optimized. Ingrowth trees are shown with lighter tone (red). Thinning years are given in parentheses

the growth of surrounding trees should also be taken into account. The degree of irregularity of the irregular stand of this study was so high that such stands are rarely encountered in managed forests. Therefore, diameter limit cutting seems to be a sufficient approach in most stands. However, there are other types of irregularity, which are more common. For example, the stand may have sub-areas of predominantly large trees while other sub-areas are occupied by smaller trees. In this case, diameter limit cutting leads to openings and unutilized growing space. Since decreased competition increases the dbh of financial maturity, it would most probably be better to leave some large trees to continue growing. This means that a tree selection rule that incorporates several criteria is more likely to work better (than dbh alone) in a wide range of stand structures. In mixed stands, relative value increment or a more complicated tree selection rule is certainly better than using only dbh to select the removed trees (Knoke 2012). This is because of differences in the inherent growth rates, assortments dimensions, and assortment prices of different species.
Although there are very few previous studies on optimal tree selection, several recent results on pre-and post-cutting diameter distributions in economically optimal uneven-aged management support the conclusion that optimal cutting resembles diameter-limit cutting (Tahvonen et al. 2010; Tahvonen 2011; Pukkala et al. 2014; Pukkala 2015a, 2015b). The American studies conducted during the 1980s lead to similar conclusions (Haight 1985, 1987; Haight and Getz 1987). Also longterm silvicultural trials support the conclusion than diameter limit cutting is more profitable than single-tree selection. For example, in the Vessari experiment located in Central Finland, the net present value (calculated with $3 \%$ discount rate) of diameter limit cutting was 13750 $€ \cdot \mathrm{ha}^{-1}$ whereas it was only $10250 € \cdot \mathrm{ha}^{-1}$ in single tree selection during a 40-year monitoring period. In the nearby Honkamäki experiment the NPV of diameter limit cutting was $10500 € \cdot \mathrm{ha}^{-1}$ and the NPV of single tree selection was $7800 € /$ ha (Pukkala et al. 2012).

The optimizations of this study were done for continuous cover management. However, the same principles of analyzing the financial maturity of trees also apply to 


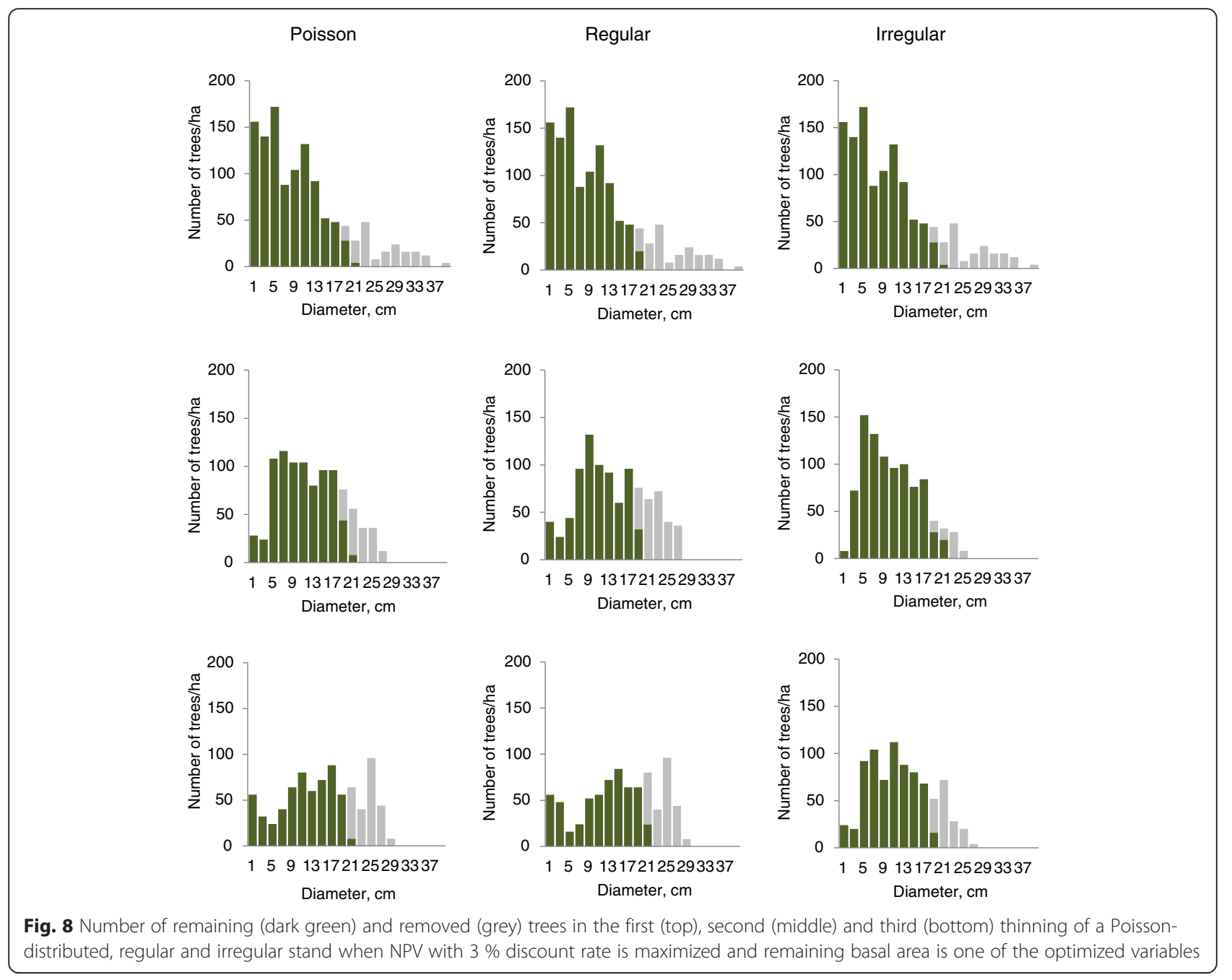

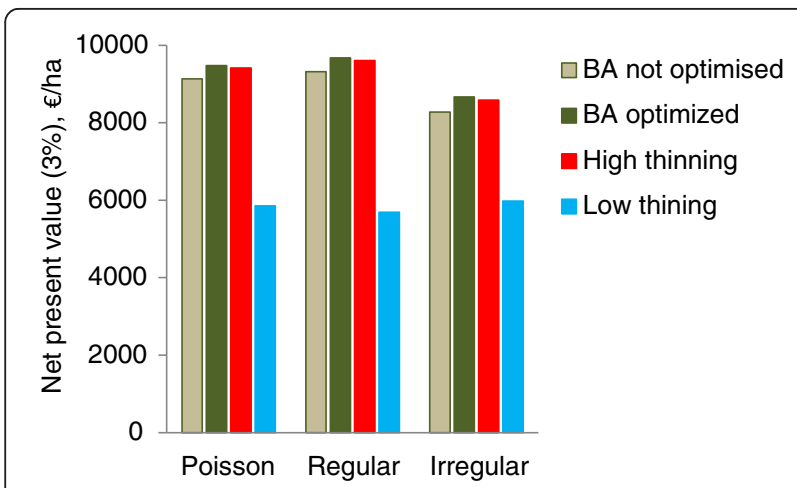

Fig. 9 Net present value when tree selection is based on optimized rule (BA not optimized, BA optimized) or on dbh (High thinning, Low thinning). In high and low thinning, the stand is thinned to the optimal remaining basal area even-aged management. Several studies have shown that the optimal thinning of a certain stand would be rather similar in even-aged management and continuous cover forestry (e.g. Pukkala 2015b). In the study of Pukkala et al. (2014), which optimized the cuttings of 200 different stands representing different stand structures without the limitation to pursue either even-aged management or continuous cover forestry, 97-99\% of thinnings were high thinnings similar to those that were found optimal in this study. However, some studies (Valsta 1992; Hyytiäinen et al. 2005; Pukkala 2015b) have found that, in evenaged management when a forced clear-felling belongs to the management schedule, it is sometimes optimal to remove trees from both ends of the diameter distribution.

Tree quality, health and vigor are additional characteristics which should affect tree selection. However, these criteria are difficult to include in simulation and optimization studies. As suggested already Möller (1922), trees whose vigor is decreased should be removed 

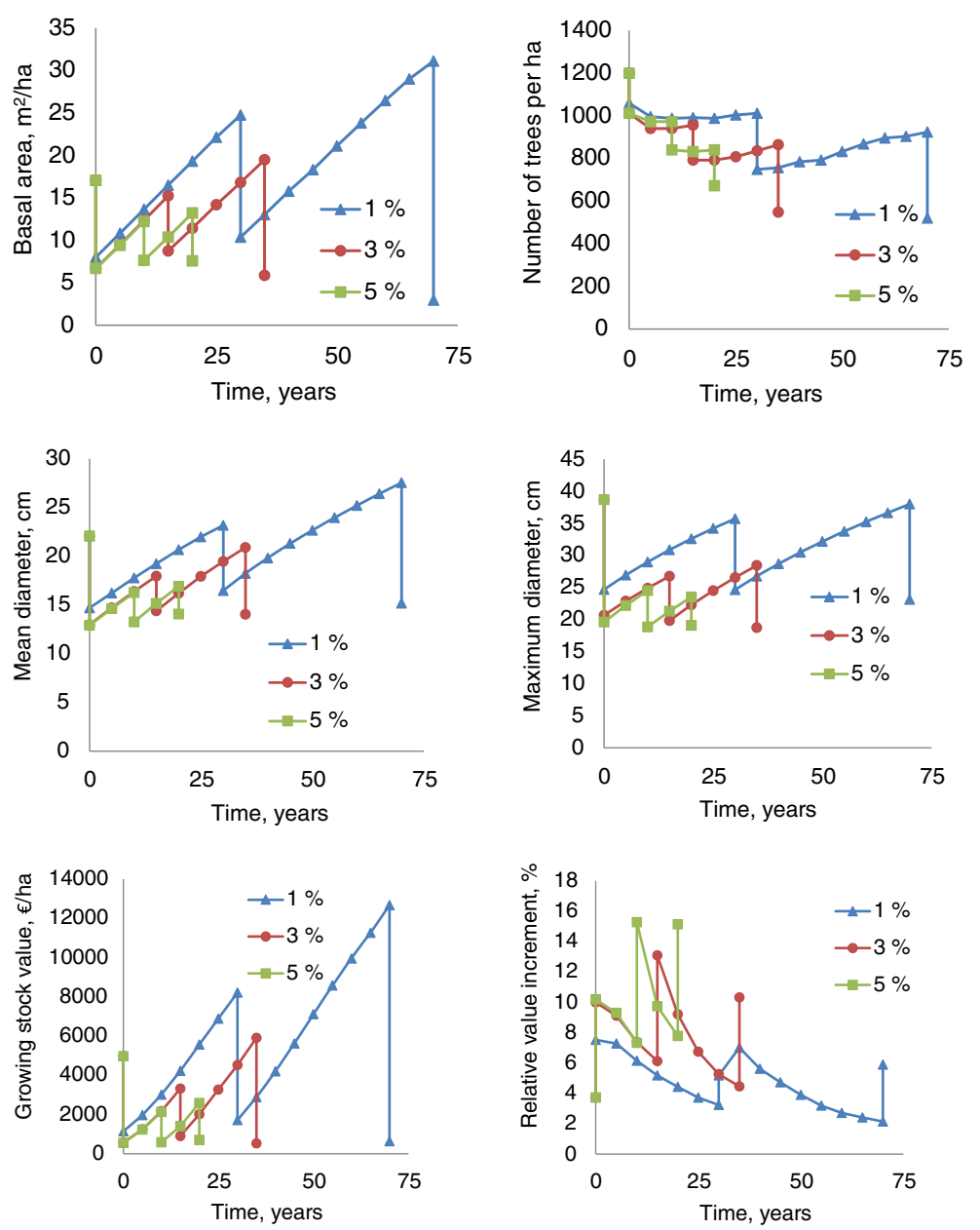

Fig. 10 Development of stand basal area, number of trees per hectare, mean diameter, maximum diameter, growing stock value and relative value increment in the optimal management schedule of the Poisson forest when NPV is maximized with 1, 3 and $5 \%$ discount rate

in thinnings. If low-quality trees overtop smaller and better-quality individuals, they should also be removed, as commonly done in forestry practice. If the quality of all trees is low (or equal), the criteria proposed in this study can be used.

The optimal tree selection rules that were developed in this study, all lead to thinning from above. The comparison of Fig. 9 also shows that thinning from below may not be economically justified. This can also be concluded from earlier literature that discusses financial maturity (Duerr et al. 1956; Davis and Johnson 1987; Knoke 2012). Also several optimization studies show that high thinning is in most cases more profitable than low thinning (e.g., Haight and Monserud 1990; Valsta 1992; Tahvonen et al. 2013). In fact, it is hard to find economic arguments which would justify the use of low thinning.

The study used a non-spatial model in spatial simulation. It was justified by the fact that the area of computing the competition variables ( $G$ and $B A L$ ) corresponds to the area of the sample plots in the modelling data of Pukkala et al. (2013). However, there is one difference: in the modelling data, $G$ and $B A L$ were computed within $300-\mathrm{m}^{2}$ plots (around $10 \mathrm{~m}$ radius) for all trees of the plot, not only for trees near plot center. These values of $G$ and $B A L$ may not describe the competition that edge trees face in the best possible way because trees outside the plot also create competition. This may be called as "sampling error" in the calculation of $G$ and $B A L$ for the edge trees in individual-tree growth modelling. Sampling error results in weaker relationship (underestimated influence) between growth and $G$ or $B A L$ in the growth model. In the current study, this underestimation was counteracted by the distance-dependent computation of $G$ and $B A L$, which increased their variation. As a result, the predictions may in fact be better than when calculating $G$ and $B A L$ in the same way as they were computed in the data preparation step of growth modelling.

The simulations of this study included stochasticity in mortality and ingrowth. Therefore, every simulation 


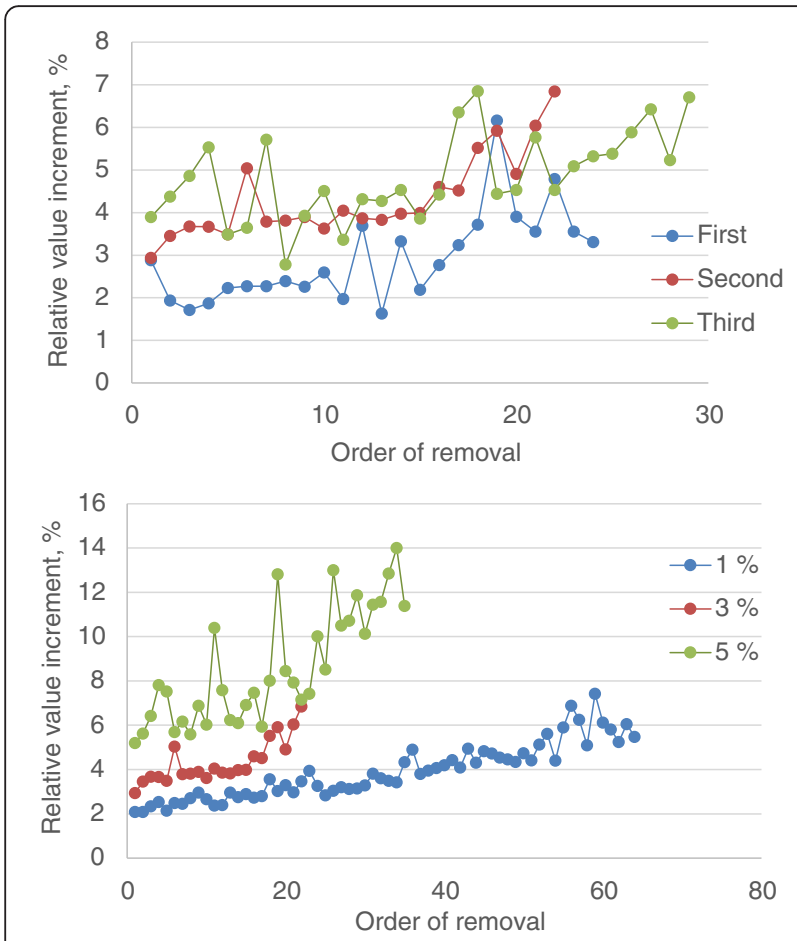

Fig. 11 Predicted value increments of removed trees in the first, second and third thinning of the Poisson stand when discount rate is $3 \%$ (top), and in the second thinning of Poisson stand when discount rate is 1,3 or $5 \%$. The relative value increments of remaining trees have been up-dated after every tree removal (for example, the relative value increment of the last tree removed is calculated for a situation in which all trees of the removal, except the last, have been removed)

was repeated 10 times and the mean $N P V$ of the 10 simulations was used as the value of the management schedule. Ten simulations is a small number in stochastic simulation. However, few trees die in managed forests, and dead trees are usually small. Ingrowth begins to affect harvest removals and stand value gradually, its effect being minimal during the first decades although ingrowth is critically important for the long-term sustainability of continuous cover forestry. Therefore, it can be concluded that the two sources of stochasticity (mortality and ingrowth) did not have any significant effect on the results of this study.

\section{Competing interests}

The authors declare that they have no competing interests.

\section{Authors' contributions}

TP conducted the analyses. EL and OL participated in the writing of the manuscript. All authors have read and approved the final manuscript.

\section{Author details}

${ }^{1}$ University of Eastern Finland, PO Box 111, 80101 Joensuu, Finland. ${ }^{2}$ Joen Forest Program Consulting, Rauhankatu 41, 80100 Joensuu, Finland.

Received: 23 September 2015 Accepted: 13 December 2015 Published online: 21 December 2015

\section{References}

Davis LS, Johnson KN (1987) Forest management. Third edition. McGraw-Hill Inc. p 790

Duerr WA, Fedkiw J, Guttenberg S (1956) Financial maturity: A quide to profitable timber growing. US Dep Agric Tech Bull 1146:74

Eerikäinen K, Miina J, Valkonen S (2007) Models for the regeneration establishment and the development of established seedlings in uneven-aged, Norway spruce dominated stands of southern Finland. Forest Ecol Manage 242:444-461

Haight RG (1985) A comparison of dynamic and static economic models of uneven-aged stand management. Forest Sci 31(4):957-974

Haight RG (1987) Evaluating the efficiency of even-aged uneven-aged stand management. Forest Sci 33(1):116-134

Haight RG, Getz WM (1987) Fixed and equilibrium problems in uneven-aged stand management. Forest Sci 33(4):908-931

Haight RG, Monserud RA (1990) Optimizing any-aged management of mixed-species stands: II. Effects of decision criteria. Forest Sci 36(1):125-144

Hooke R, Jeeves TA (1961) "Direct search" solution of numerical and statistical problems. J ACM 8:212-229

Hyytiäinen K, Tahvonen O, Valsta L (2005) Optimum juvenile density, harvesting and stand structure in even-aged Scots pine stands. Forest Sci 51:120-133

Knoke T (2012) The economics of continuous cover forestry. In: Pukkala T, Gadow KV (eds) Continuous Cover Forestry. Springer. ISBN 978-94-007-2201-9. pp 167-193

Laasasenaho J (1982) Taper curve and volume equations for pine spruce and birch. Communicationes Instuti Forestalis Fenniae 108:1-74

Miina J, Pukkala T (2000) Using numerical optimization for specifying individual-tree competition models. Forest Sci 46(2):277-281

Möller A (1922) Der Dauerwaldgedanke: sein Sinn und seine Bedeutung. Springer, Berlin, $\mathrm{p} 84$

Pukkala T (2015a) Optimizing continuous cover management of boreal forest when timber prices and tree growth are stochastic. Forest Ecosyst 2(6):1-13

Pukkala T (2015b) Plenterwald, Dauerwald, or clearcut? Forest Policy Econ 2016(62):125-134, http://dx.doi.org/10.1016/j.forpol.2015.09.002

Pukkala T, Miina J (1998) Tree-selection algorithms for optimizing thinning using a distance-dependent growth model. Can J Forest Res 28:693-702

Pukkala T, Lähde E, Laiho O (2012) Continuous cover forestry in Finland - Recent research results. In: Pukkala T, Von Gadow K (eds) Continuous Cover Forestry. Springer., pp 85-128

Pukkala T, Lähde E, Laiho O (2013) Species interactions in the dynamics of even- and uneven-aged boreal forests. J Sustain Forest 32:1-33

Pukkala T, Lähde E, Laiho O (2014) Optimizing any-aged management of mixed boreal forest under residual basal area constraints. J Forest Res 23(3):727-636

Tahvonen O (2011) Optimal structure and development of uneven-aged Norway spruce forests. Canadian Journal of Forest Res 42:2389-2402

Tahvonen O, Pukkala T, Laiho O, Lähde E, Niinimäki S (2010) Optimal management of uneven-aged Norway spruce stands. Forest Ecol Manage 260:106-115

Tahvonen O, Pihlainen S, Niinimäki S (2013) On the economics of optimal timber production in boreal Scots pine stands. Can J Forest Res 43:719-730

Valsta L (1992) A scenario approach to stochastic anticipatory optimization in stand management. Forest Sci 38(2):430-447

\section{Submit your manuscript to a SpringerOpen ${ }^{\circ}$ journal and benefit from:}

- Convenient online submission

- Rigorous peer review

- Immediate publication on acceptance

- Open access: articles freely available online

- High visibility within the field

- Retaining the copyright to your article

Submit your next manuscript at $>$ springeropen.com 